\title{
Impact phenomena assessment: Part I - Structural performance of a tanker subjected to ship grounding at the Arctic
}

\author{
Aditya Rio Prabowo ${ }^{1}$, Jung Hoon Byeon ${ }^{1}$, Hyun Jin Cho ${ }^{1}$, Jung Min Sohn ${ }^{1,2, *}$, \\ Dong Myung Bae ${ }^{2}$ and Joung Hyung $\mathrm{Cho}^{1}$ \\ ${ }^{1}$ Pukyong National University, Marine Convergence Design, 48513 Busan, Korea \\ ${ }^{2}$ Pukyong National University, Naval Architecture and Marine Systems Eng., 48513 Busan, Korea
}

\begin{abstract}
The remarkable influence of the global warming to Arctic environment opens a possibility to conduct a voyage from Asia to Europe through the Northern Sea Route (NSR). This option is considered as a decent solution to reduce fuel consumption and increase time efficiency in delivering cargo to the designated destination. However, this alternative comes with a challenge to keep safety of ship structures against an impact with obstacles which are possibly encountered at the Arctic. Solid ice can be considered as a serious threat to the double bottom of ship structures in impact phenomena, especially ship grounding. In this work, a series of grounding calculations are conducted to produce estimation of structural crashworthiness during interaction between double bottom and conical type ice. Material characteristics based on tensile testing of polar class material are applied to calculation and compared with non-polar steel.
\end{abstract}

\section{Introduction}

In recent decades, a global warming has become an attractive issue for many countries. High increment of carbon dioxide $\left(\mathrm{CO}_{2}\right)$ concentration in the air is followed by the remarkable changes in temperature. In southern region, this phenomenon has a strong influence to human activity. During summer, the greenhouse effect influences water crisis in Asia and Africa. On the other hand, a serious challenge is faced to the society in northern region as high temperature during summer reduces Arctic sea-ice extent [1]. International shipping societies and parties show their interest to observe this opportunity as an alternative route to reach Europe from Asia. A comparative study indicates that the operational cost and sailing time can be considerably reduced using Arctic Sea route [2]. Despite of this positive tendency, a negative influence of ice and other obstacles cannot be neglected. Maritime accidents in forms of collision and grounding impacts are considered as high risks since casualties (e.g. human life loss, oil spill, cargo lost) are massive. Several studies [3-4] for maritime accidents and impact phenomena have been conducted to observe structural crashworthiness of ship under various conditions. However, the analysis conditions have not been addressed to reflect the condition of the Arctic.

\footnotetext{
* Corresponding author: jminz@pknu.ac.kr
} 
The aim of this study is to assess crashworthiness of a tanker ship against the grounding. A temperature level of the Arctic is considered based on the survey and reports of related parties. Series of tensile tests in the low temperatures [5] are used as a reference data to define mechanical properties of ship materials. Numerical analysis is conducted under determined scenarios to provide structural behaviour during and after impacts.

\section{Water temperature and polar classification}

The effect of global warming on sea temperature at the Arctic has caused changes in almost every physical climate system. As reported by Hassol [1], there are at least three climate trends in this region. The first is the rising temperature. In winter, the temperature is increased in Alaska and western Canada approximately $3-4^{\circ} \mathrm{C}$ over the past half-century. The second is declining snow cover. It has declined about $10 \%$ over the past 30 years. The third is diminishing lake and river ice. The tendency is concluded that later freeze-up and earlier break-up of river and lake ice have combined to reduce ice season one to three weeks in several areas. Emissions of daily activity also cause heat up and more than $93 \%$ of this temperature increment goes to the ocean. In the investigation by Northern Europe countries, it was concluded that sea temperature is $-40^{\circ} \mathrm{C}$ in January and can drop until $50^{\circ} \mathrm{C}$ over large parts of the Arctic in winter. Emerson and Lahn [6] presented that winter temperature reaches the most extreme temperature $-50^{\circ} \mathrm{C}$ at the Laptev Sea.

In the initial requirement, International Association of Classification Society (IACS) divides the Polar Class into seven classes [7] depending on the operating season and ice conditions. A simpler classification is presented in Fig. 1 as recommended by International Maritime Organization (IMO) which divides ships based on the water condition and structural risks [8]. Based on this regulation, both IACS's polar class designation and IMO's C-class which is not applied by ice-strengthening can operate at the Arctic.

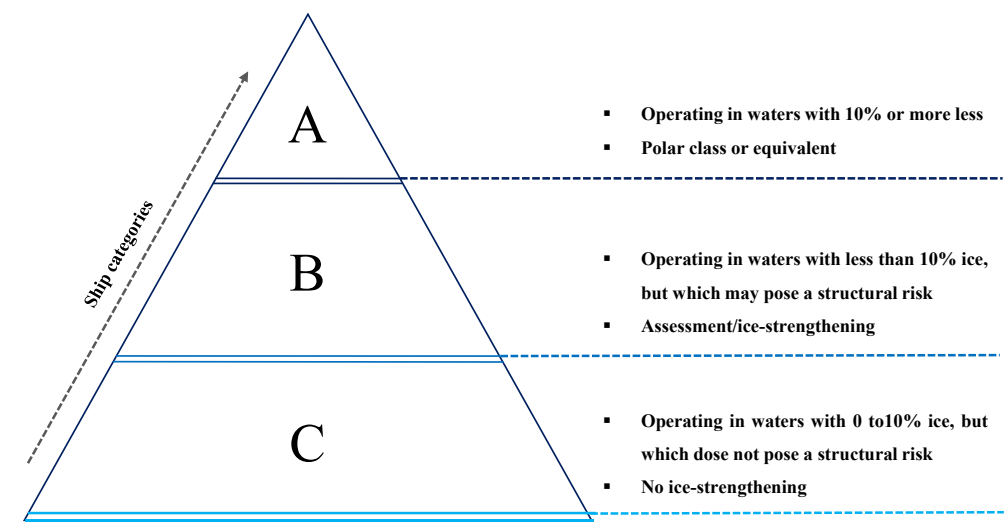

Fig. 1. Ship classification on the Polar Regions. Illustration is presented based on reference [8].

\section{Numerical model and analysis configuration}

\subsection{Ship dimension and finite element setting}

A C-class tanker vessel based on IMO is deployed in this study as the target ship. The tanker has principal dimensions as follows: Length $L=144 \mathrm{~m}$, Width $B=22.6 \mathrm{~m}$ and Depth $H=13.95 \mathrm{~m}$. Double bottom structure is designed for a numerical simulation with approximately $15 \mathrm{~m}$ or equal with two cargo tanks in order to avoid interference of boundary condition. A grounding scenario is simulated by finite element codes ANSYS LS- 
DYNA [9]. Considering complex behaviour of the grounding process, the element formulation with fully integrated type of the Belytschko-Tsay is implemented on the structure. The material characteristics for the ship are idealized as plastic-kinematic model with kinematic hardening. Properties of a typical HSLA steel are given as follows: Elastic modulus $E=210000 \mathrm{MPa}$, Yield strength $\sigma_{Y}=315 \mathrm{MPa}$, Poisson's ratio $n=0.3$, and Density $\rho=7850 \mathrm{~kg} / \mathrm{m}^{3}$. Nonlinear parameters are described using the Cowper-Symonds strain rate $c=3200 / \mathrm{s}$ and $P=5[10]$. These properties are denoted as the non-polar class.

As introduced in previous sections, the study is addressed to observe structural crashworthiness at the Arctic. Therefore, results from tensile tests in extreme temperatures [5] are used to investigate the structural behaviour under grounding impacts. The material is tested under three different temperatures, including room temperature $(\mathrm{RT}),\left(-30^{\circ} \mathrm{C}\right)$ and $(-$ $\left.50^{\circ} \mathrm{C}\right)$. The results are adequate to represent the Arctic conditions as the most extreme temperature during winter is included in this test. The material of the tensile tests will be denoted as the polar class and for the temperatures RT, $\left(-30^{\circ} \mathrm{C}\right)$ and $\left(-50^{\circ} \mathrm{C}\right)$, ordinal numberings I, II and III are given consecutively. Variety of material strength in each temperature is summarized as: the polar class I $\left(\sigma_{Y-\mathrm{I}}\right)=385.05 \mathrm{MPa}$, polar class II $\left(\sigma_{Y-\text { II }}\right)=$ 425.27 $\mathrm{MPa}$ and polar class III $\left(\sigma_{Y}-\right.$ III $)=448.01 \mathrm{MPa}$. During numerical simulation, an indenter with applied ice material is deployed. The ice is treated as a solid-rigid material. This approach is a conventional but it is considered good enough to estimate the most extreme damage extents in the worst-case scenario. It is because that the indenter does not undergo deformation and can produce steady-damage geometrically during penetrations. Properties of the ice are given as follows: Poisson's ratio $n=0.27$, Young's modulus $E_{x}=$ $1000 \mathrm{MPa}$ and density $\rho=960 \mathrm{~kg} / \mathrm{m}^{3}$. As indicated in pioneer works [3-4], the failure criterion is necessary to be involved in calculation. The Peschmann criterion [11] is applied in this work which concludes the element length of the engineering models is $150 \mathrm{~mm}$ and failure strain for the double-bottom structure is 0.21 . The friction between ice and steel is considered very low with the static friction coefficients $\eta_{s}=0.06$ and kinematic friction coefficient $\eta_{k}=0.05$ are applied.

\subsection{Collision scenario}

Grounding is defined as the interaction process between the structure and obstacle during the movement process. In this process, the involved models are classified as the structure for the double bottom and obstacle for the conical ice. A specific target on the structure is denoted as the impact area. The structure is given a constant velocity $7 \mathrm{~m} / \mathrm{s}$ to move on the positive longitudinal direction ( $x$ axis) according to the Cartesian coordinate system and approaching the obstacle.

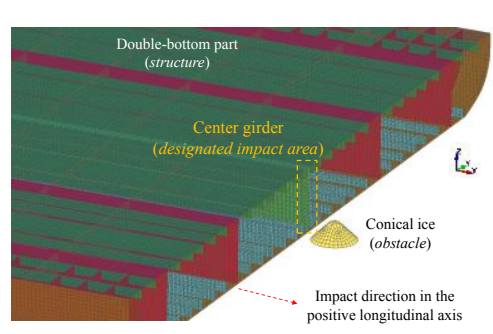

Isometric view

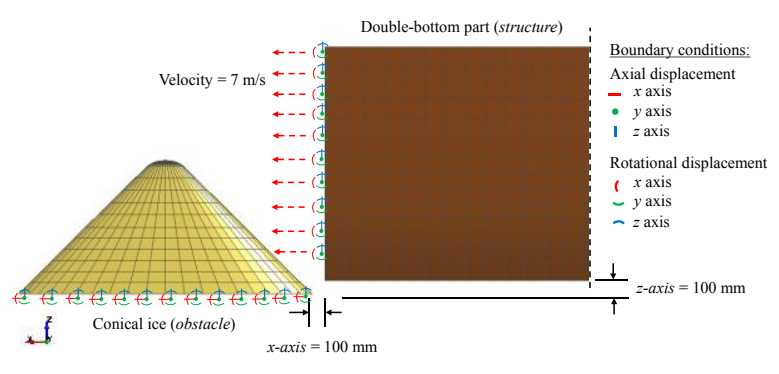

Side view

Fig. 2. Model of the double bottom tanker. The yellow highlights the target part in grounding process. 
Initial distance (Fig. 2) between the structure and obstacle is determined $100 \mathrm{~mm}$ in both longitudinal and vertical directions ( $x$ and $\mathrm{z}$ axes). Axial constraint is applied on the end of the structure model. Rotational movement of the bottom and inner bottom plates in this location is also restrained to keep the models stand-still on the centerline. Evaluation is focused on the occurred energy and strain behaviour on the structure due to the grounding.

\section{Results and Discussion}

During grounding, it is fundamentally assumed that the most remarkable damage will be observed in the bottom plate. Its position on the lowest part of the double bottom makes the bottom plate experiences various damages, such as tearing damage in head-on grounding. Even though the center girder was included as the designated impact area, Fig. 3a indicates that the highest energy was achieved by the bottom plate. In this discussion, the internal energy is determined as a main parameter which reflects the amount of energy that is necessary to plastically deform the involved structures in impact $[3,4,10]$. More detail observation is conducted on the polar class materials while failure took place. At the first contact between the obstacle and structure (Fig. 3a), both center girder and bottom shell showed similarity in pattern and magnitude of the internal energy. In terms of the center girder as the designated impact area, a difference was observed after $0.09 \mathrm{~s}$ which indicated that the transition from a deformation state to the failure condition. On the other hand, the bottom shell experienced higher damage than the center girder, the transition was began earlier than the center girder. This phenomenon occurred due to the increasing size of lower part of the conical ice. The larger diameter produced earlier contact and made the structure experienced early failure. In extreme temperatures, the Polar classes II and III showed relatively distinction approximately after $0.12 \mathrm{~s}$ for the center girder and $0.075 \mathrm{~s}$ for the bottom shell. It is concluded that the structural resistance against the impact for the ship using Polar class material is more effective during operation in low temperature region.

a

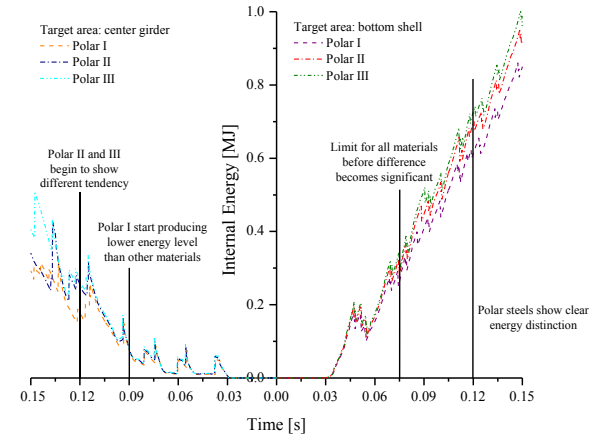

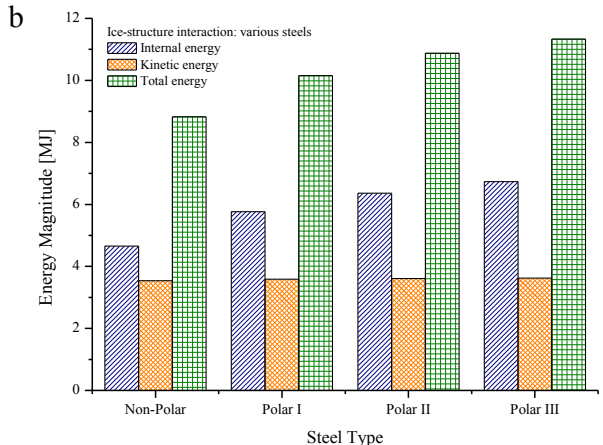

Fig. 3. Crashworthiness criteria: (a) internal energy of the girder and shell under several temperatures and (b) statistical data of the calculated energies after impact with different material properties.

The statistical comparison in terms of energy is presented in next discussion for the non-polar and polar materials. There are three main energies which are shown in Fig. 3b, namely internal, kinetic and total energies. As mentioned in fundamental concept of physic, the kinetic or kinematic energy is an amount of the energy to move an object from one location to others. Since constant velocity was applied in the methodology, the kinetic energy is observed similar for all materials. This result is a satisfactory in confirming grounding process since the kinetic energy should not have significant difference if the constant velocity is applied. The total energy is roughly translated as the summary of the kinetic and internal energies in impact. As the constant velocity was implemented, the total 
energy highly depends on by the internal energy. According to tensile test in extreme temperatures, polar class materials have a characteristic to increase their strength as a temperature goes down [5]. This characteristic was indicated a match with the energy magnitude that the total energy for the polar class III in the lowest temperature $\left(-50^{\circ} \mathrm{C}\right)$ was the highest and it was harder to be plastically deformed in grounding than other polar material. The overall results in terms of total energy also conclude that the polar class material is harder than the marine steel (non-polar class) which is intended for ship in sea with normal temperature.
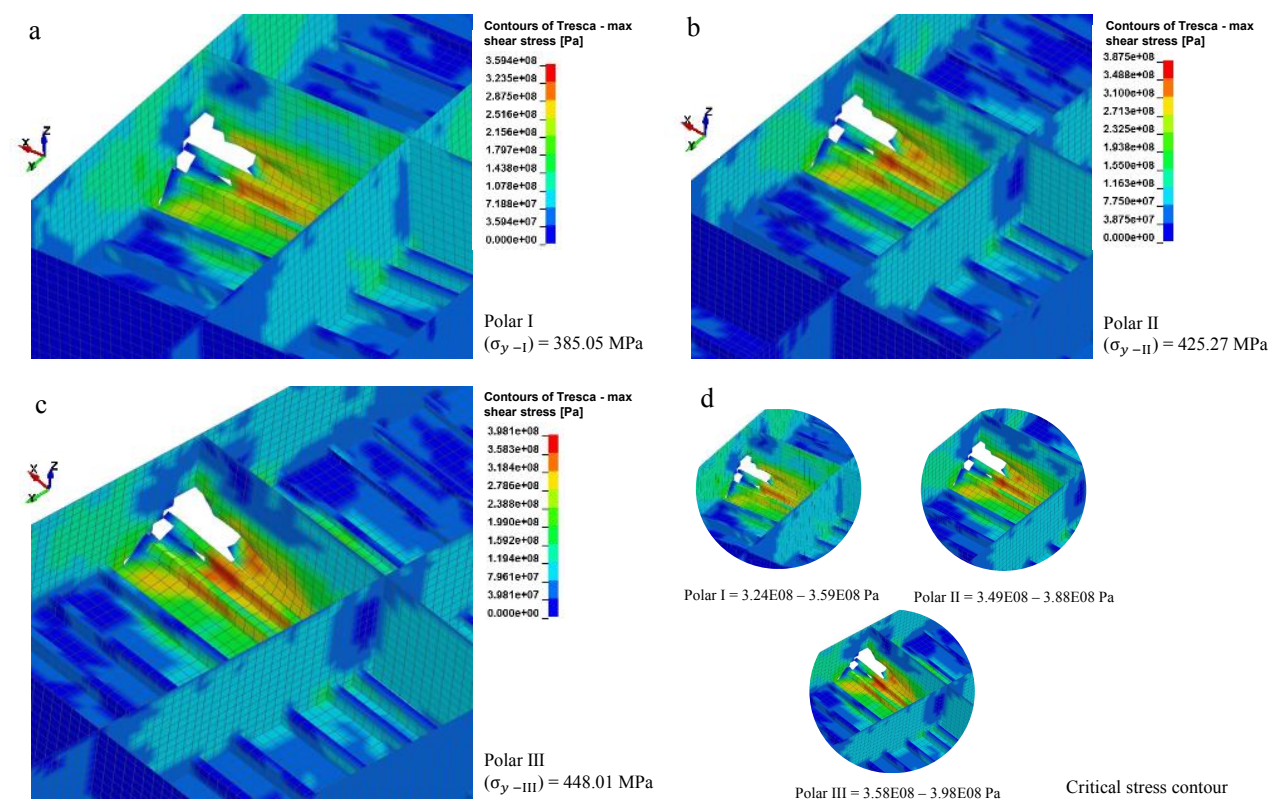

Fig. 4. Shear stress (Tresca) accounting for the selected materials: (a) Polar I, (b) Polar II, (c) Polar III and (d) summary of the maximum stress values.

After comparison in terms of energy, the discussion is directed to the extent of damage after grounding. In order to describe this behavior, Tresca stress contour is chosen to be discussed and presented in Fig. 4. Fundamental expression of the Tresca is also used as failure criterion for structures under various loads together with the von Mises formulation. Historically, the Tresca was considered more fundamental, but the von Mises was seen more appealing for convenient approximation [12]. Similar works have used the von Mises as found in $[4,13]$ which lead this work to observe Tresca contour. In comparing the material strength (Fig. 4a-c), the Polar III is superior to the Polar I and II with difference approximately $9.45 \%$ and $5.06 \%$ consecutively. The highest stress on the structure indicates that Tresca stress reached its peak on the bottom shell and bottom stiffener. This behavior made these components would experience early failure if the grounding was continued. Distinction on the peak value as shown in Fig. $4 \mathrm{~d}$ is found $7.47 \%$ and $2.51 \%$ for Polar I-III and Polar II-III. The highest stress on the bottom area has successfully confirmed pioneer discussion on the internal energy that the shell produced higher energy than the center girder in grounding. Correlation between these two behaviors can be concluded that harder an object to be plastically deform in impact will experience higher stress level. Accounting for the failure prediction, if grounding time is expanded and similar indenter with this work is applied, early failure of the bottom shell is highly expected. Since conical indenter was applied in analysis, the lower part of the structure (in this case is bottom shell and bottom stiffener) will contact with the largest diameter of the indenter. Thus, the highest stress 
occurred on the bottom shell and among of all applied materials, the experienced stress was produced during a ship voyage was conducted on the most extreme temperature at the Arctic. Based on this study, it can be stated that contribution of the polar class material is relatively high to the double bottom strength depends on the environment temperature. In order to increase structural strength against impact, polar class material can be applied on non-polar class ships (C-class) which operate through the North Sea passage, as adequate replacement of ice-strengthening requirement as explicitly stated for A and B-class on the polar operating ship categories [8].

\section{Conclusion}

This work was addressed to observe crashworthiness criteria and failure progress of the applied polar class material on the double bottom structure. Comparison with non-polar steel was presented in the initial discussion which was followed by a series of discussion in terms of temperature influence to the energy and stress. It was concluded that the material for operation in extreme regions such as Northern Sea Route has stronger characteristic than a ship material for sailing in general sea territory as can be found in the Southern Sea Route. The internal energy which is related to structural strength against impact provides a conclusion that resistance by the polar class material reaches its peak during ship operation in winter since sea temperature drops to $50^{\circ} \mathrm{C}$ below zero in this season. Stress behaviour of three materials on the double bottom structure satisfyingly confirmed strength-stress relationship in the grounding. Consideration to apply polar class material on the c-class ships which operate at the Arctic is encouraged to increase its safety against impact.

\section{Reference}

1. S.J. Hassol, Impact of a warming arctic (Cambridge University Press, Cambridge, 2004)

2. W. Østreng, K.M. Eger, B. Fløistad, A.J. Dahl, L. Lothe, M.M. Larsen, T. Wergeland, Shipping in arctic waters, A comparison of the northeast, northwest and trans polar passages (Springer-Verlag, Berlin, 2013)

3. A.R. Prabowo, D.M. Bae, J.M. Sohn, A.F. Zakki, B. Cao, J.H. Cho, Thin-Walled Struct. 115, 225 (2017)

4. A.R. Prabowo, B. Cao, D.M. Bae, S.Y. Bae, A.F. Zakki, J.M. Sohn, Lat. Am. J. Sol. Struct. 14, 1106 (2017)

5. D.K. Min, C.K. Shim, D.W. Shin, S.R. Cho, J. Soc. Nav. Arc. Korea 48, 171 (2011)

6. C. Emmerson, G. Lahn, Arctic opening: opportunity and risk in the high north (Lloyd's, London, 2012)

7. IACS, Requirements concerning polar class, Rev.2 (International Association of Classification Societies, London, 2016)

8. D.K. Park, D.K. Kim, J.K. Seo, B.J. Kim, Y.C. Ha, J.K. Paik, Ocean Eng. 102, 197 (2015)

9. ANSYS, ANSYS LS-DYNA user's guide (ANSYS, Inc., Pennsylvania, 2017)

10. O. Ozguc, P.K. Das, N. Barltrop, Mar. Struct. 18, 511 (2005)

11. E. Lehmann, J. Peschmann, Mar. Struct. 15, 429 (2002)

12. A.R. Prabowo, S.J. Baek, H.J. Cho, J.H. Byeon, D.M. Bae, J.M. Sohn, Lat. Am. J. Sol. Struct. 14, 1345 (2017)

13. A. AbuBakar, R.S. Dow, Int. J. Sol. Struct. 50, 623 (2013) 